\title{
Investigation on stress micro-cycles and mild wear mechanism in gear contact fatigue
}

\author{
Ye Zhou ${ }^{1}$, Caichao Zhu ${ }^{1}$, Huaiju Liu ${ }^{1}$, Houyi Bai ${ }^{2}$, and Xiaona Xu ${ }^{2}$ \\ ${ }^{1}$ Chongqing University \\ ${ }^{2}$ Chongqing Wangjiang Industrial Co.
}

January 8, 2021

\begin{abstract}
Gear contact fatigue is becoming a primary limitation for the growing demand of power density and service life in gear-driven equipment. The unchecked surface fatigue crack could further cause premature failure and put a serious risk to the safety and reliability of mechanical systems. In this work, an attempt is made to investigate the effects of rolling-sliding and mild wear on contact fatigue behavior. A comprehensive contact model is developed to capture the variation instantaneous pressure and stress field is calculated with the transient mixed EHL approach. Rolling-sliding contact is simulated with the time-varying roughness topography updated by Archard wear equation. The stress cycles are extracted and the relative contact fatigue life is obtained by using Zaretsky criterion. Results suggest that in rolling-sliding contact the contact fatigue life is obviously lower compared with pure rolling. The increases in the number and amplitude of stress micro-cycles is found to be the main contributors to the reduction of fatigue life. Mild wear tends to smooth the surface, subsequently mitigates the stress concentration and reduces stress cycles, then decrease the risk of surface contact fatigue.
\end{abstract}

\section{Hosted file}

Manuscript0102.pdf available at https://authorea.com/users/388240/articles/503067investigation-on-stress-micro-cycles-and-mild-wear-mechanism-in-gear-contact-fatigue 


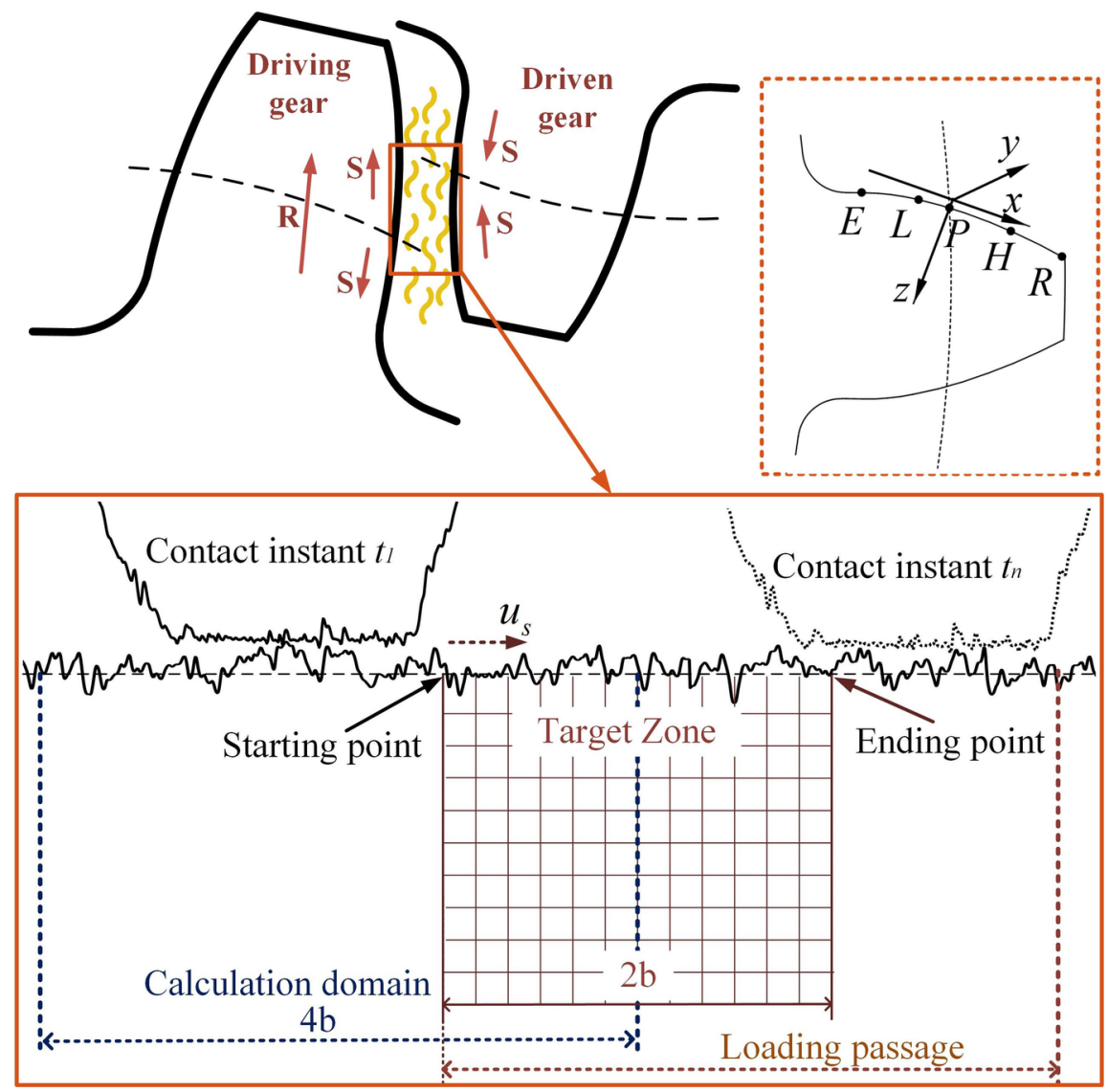




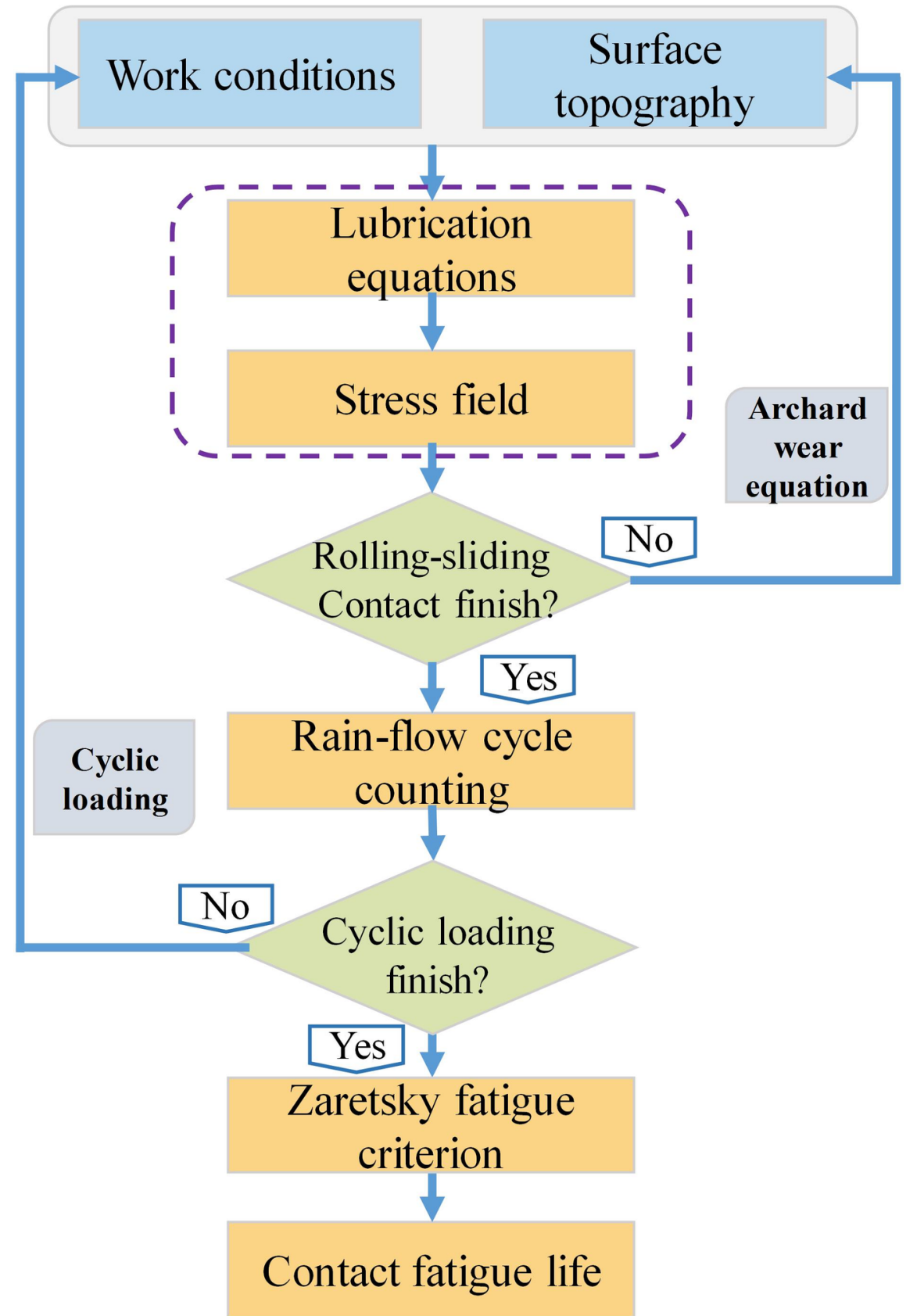



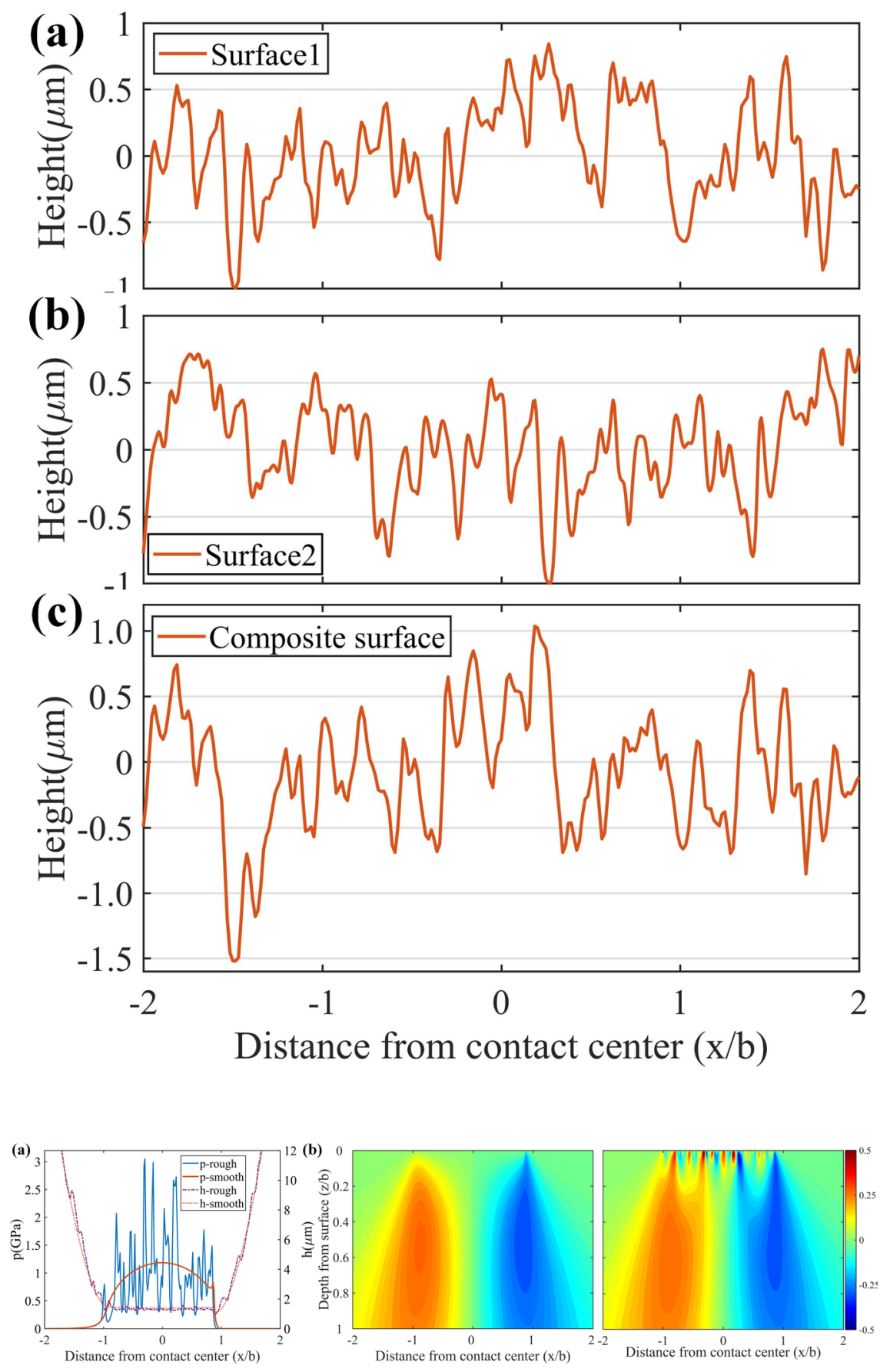

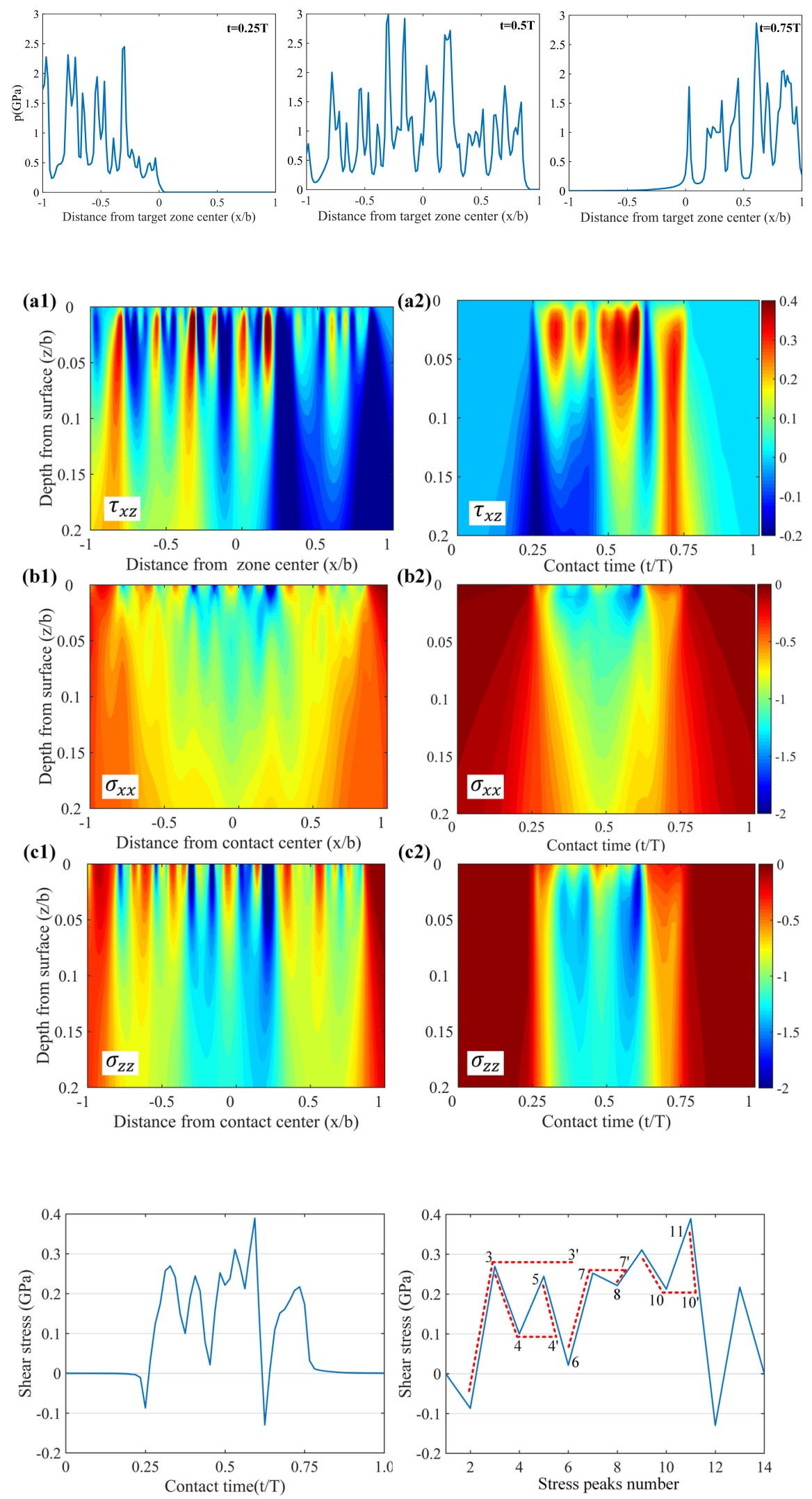

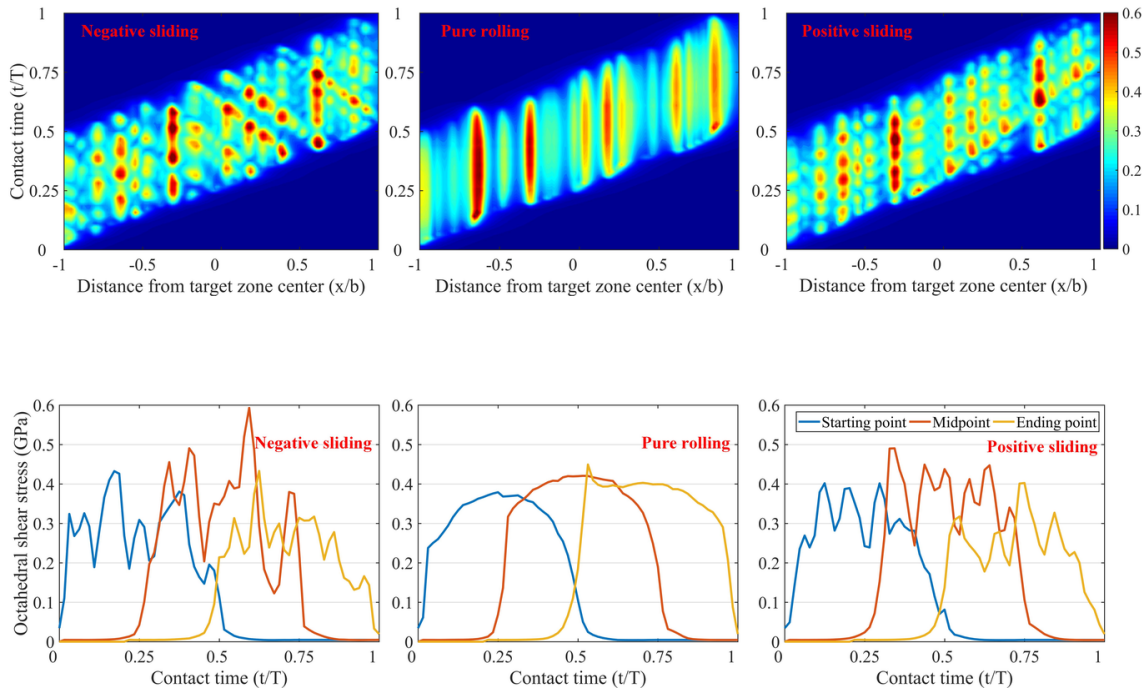

(a)
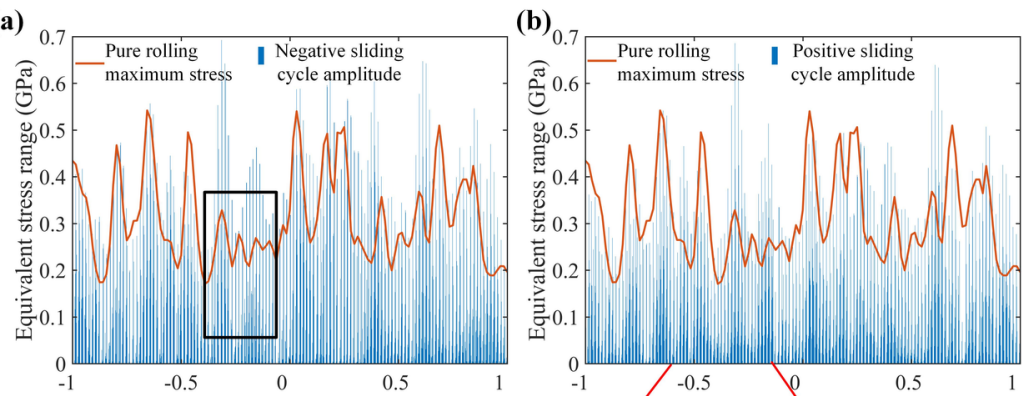

(c)

(d)
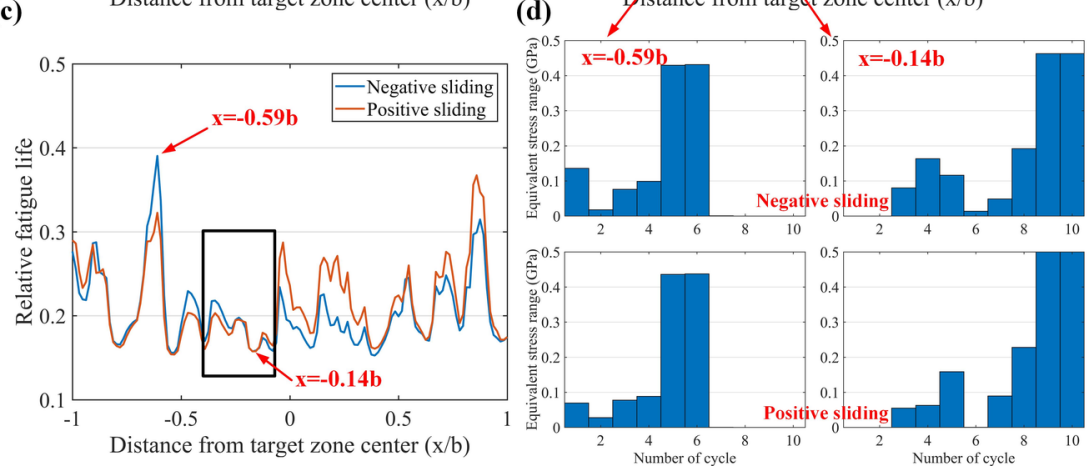

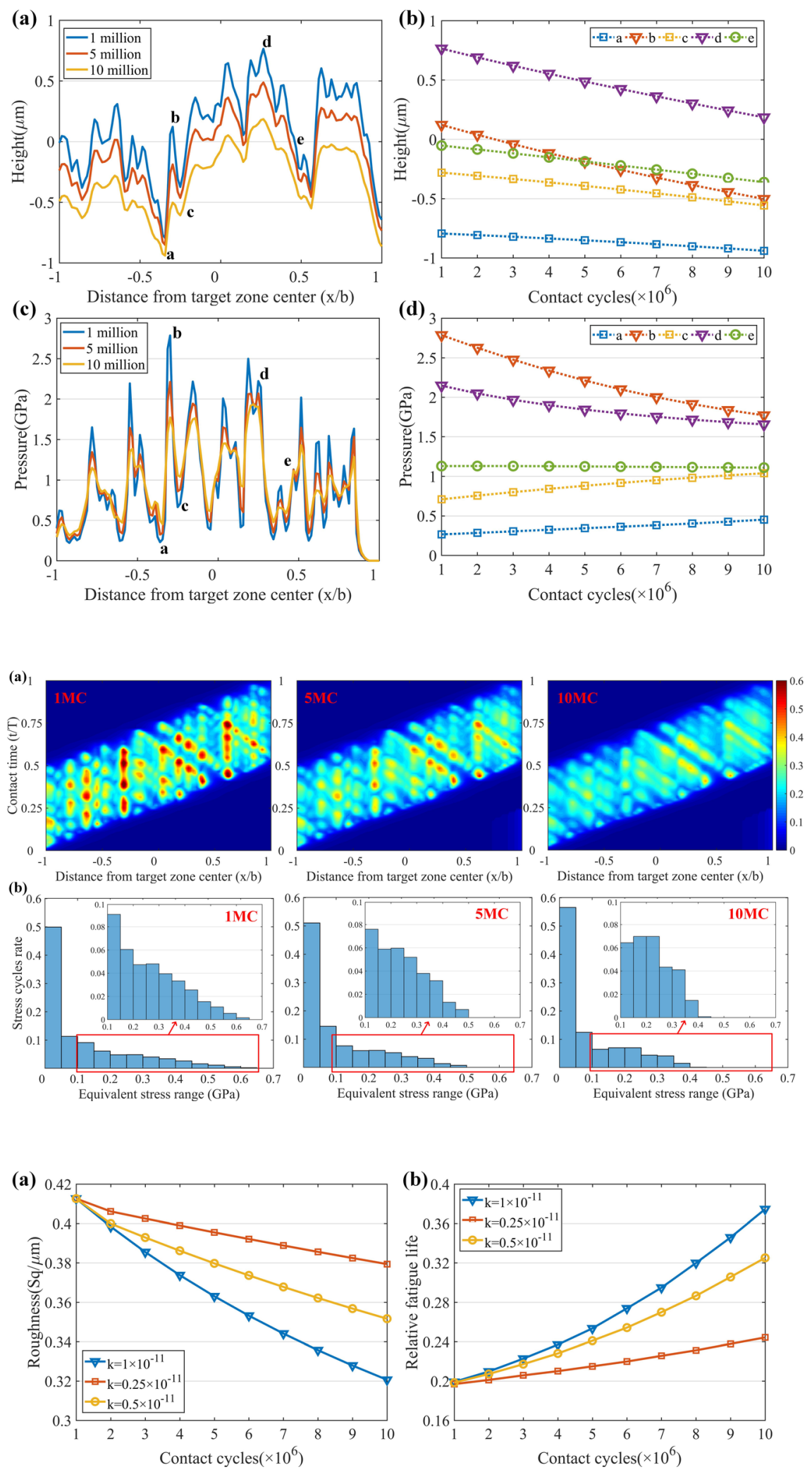

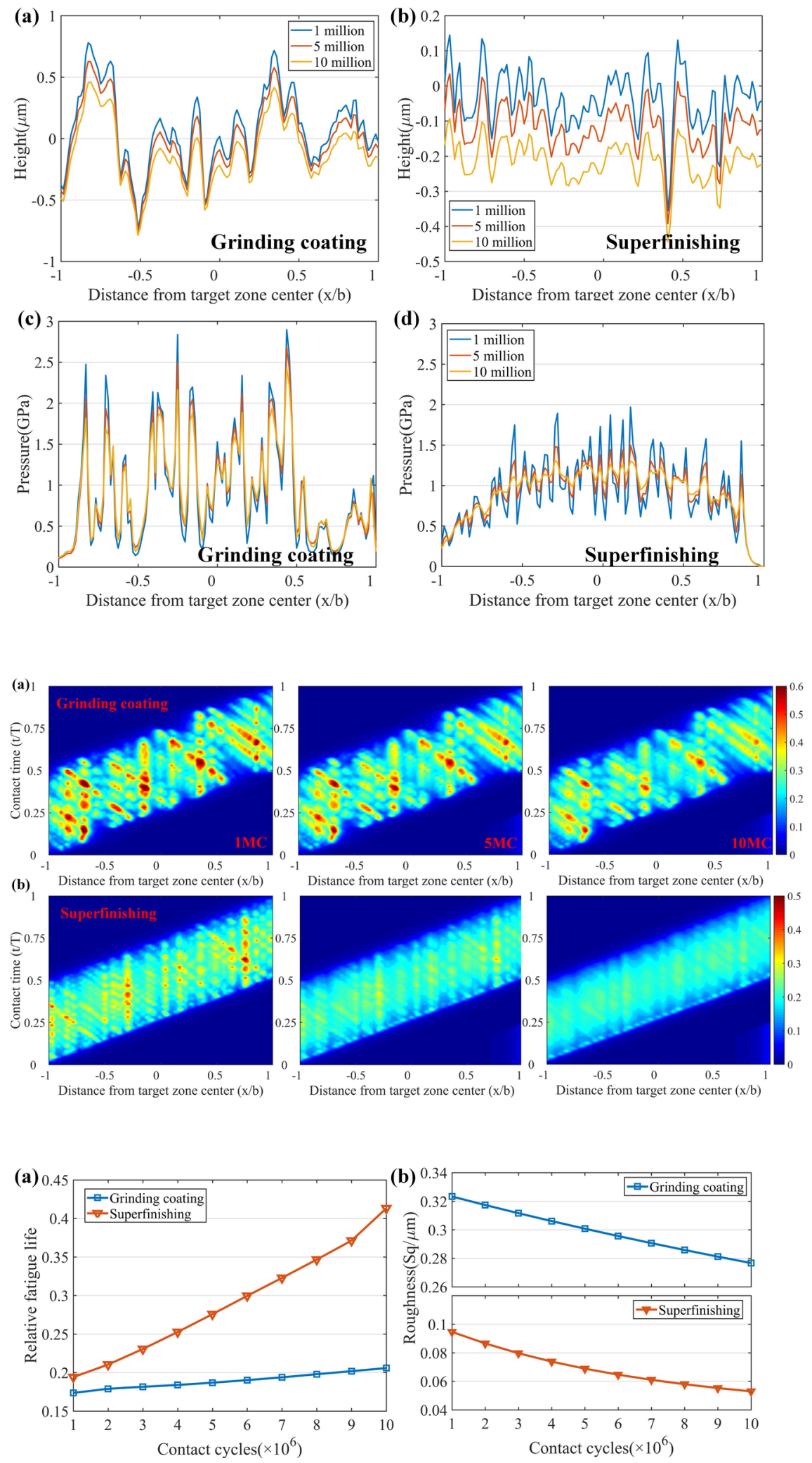